\title{
LT $\beta R$ expression on hematopoietic cells regulates acute inflammation and influences maturation of myeloid subpopulations
}

Innate Immunity 20I4, Vol. 20(5) 46I-470 (C) The Author(s) 2013 Reprints and permissions: sagepub.co.uk/journalsPermissions.nav DOI: 10.1 I77//7534259/3497242 ini.sagepub.com

SAGE

\author{
Anja K Wege ${ }^{1,2}$, Barbara Huber', Nadin Wimmer', \\ Daniela N Männel' and Thomas Hehlgans'
}

\begin{abstract}
Lymphotoxin beta-receptor (LT $\beta R$ ) is involved in the formation and maintenance of secondary lymphoid structures, as well as in the regulation of inflammatory responses. Because LT $\beta R$ lymphoid structure formation continues to develop in infants, we compared two different chimera models: one using adult mice and the other using a transplantation model of neonatal mice. To elucidate the function of LT $\beta R$ on lymphoid and non-lymphoid cells, we generated bone marrow chimeras on the wild type C57BI/6 and the LT $\beta R$-deficient $\left(\mathrm{LT} \beta \mathrm{R}^{-1-}\right.$ ) background, and reconstituted the mice with bone marrow cells reciprocally. These chimeric mice were analyzed in the experimental model of acute dextran sulfate sodium-induced colitis. Interestingly, both models revealed not only equal reconstitution levels but also similar immunological responses: LT $\beta R$ expression on stromal cells is essential for lymph node formation, whereas LTBR on hematopoietic cells is crucial for a decrease in inflammation. In addition, mice lacking LT $\beta R$ on hematopoietic cells revealed (a) an increase of immature granulocytic cells in the spleen and (b) a reduced proportion of myeloid cells in peripheral blood and spleen expressing $\mathrm{CDI} \mathrm{Ib}{ }^{+} \mathrm{Ly} 6 \mathrm{C}^{+} \mathrm{Ly}_{6 \mathrm{G}}{ }^{-}$(myeloid-derived suppressor cells expression profile). In conclusion, LT $\beta R$ expression on hematopoietic cells seems to be involved in the down-regulation of acute inflammatory reactions paralleled by the appearance of immature myeloid cells.
\end{abstract}

\section{Keywords}

Bone marrow chimera, dampening inflammation, DSS-induced colitis, LT $\beta R$, MDSC

Date received: 10 April 2013; revised: 23 May 2013; accepted: 44 June 2013

\section{Introduction}

Lymphotoxin beta-receptor (LT $\beta \mathrm{R})$ signaling is involved in lymphoid organogenesis and the maintenance of secondary lymphoid structures, ${ }^{1-3}$ as well as the regulation of acute inflammatory reactions. ${ }^{1}$ Recent studies described the importance of LT $\beta R$ during dextran sulfate sodium (DSS)-induced colitis by inhibition of LT $\beta$ R activation. ${ }^{4-6}$ Blocking of LT $\beta$ R signaling was achieved either by treatment with LT $\beta \mathrm{R}-\mathrm{Ig}$, a functional inhibitor of LT $\beta R$ signaling, or by congenital deletion of the LT $\beta R$ or its functional ligand lymphotoxin (LT) $\alpha_{1} \beta_{2}$.

LT $\beta R$ also seems to be involved in the recruitment of different hematopoietic cells in lymphoid and nonlymphoid compartments, including the recruitment of $\mathrm{B}$ cells into the intestine ${ }^{7}$, denditric cells (DC) into the spleen in particular and in lymphoid tissues in general. ${ }^{8,9}$
LT $\beta R$ signaling is also essential for the development and function of high endothelial venules, ${ }^{10}$ the induction of lymphoid tissue chemokines and adhesion molecules ${ }^{11}$ and the expression of mucosal addressin cell adhesion molecule-1 in DSS-induced intestinal inflammation. ${ }^{12}$ These findings reveal the importance of LT $\beta R$

\footnotetext{
'Institute of Immunology, University of Regensburg, Regensburg, Germany

${ }^{2}$ Clinic of Gynecology and Obstetrics, Caritas Hospital St. Josef, University of Regensburg, Regensburg, Germany

\section{Corresponding author:}

Anja K. Wege, Clinic of Gynecology and Obstetrics, Caritas Hospital St. Josef, University of Regensburg, Franz-Josef-Strauss-Allee II, Regensburg 93053, Germany.

Email: Anja.Wege@klinik.uni-regensburg.de
} 
and ligand interaction in the control of the trafficking of lymphoid cells.

In addition, LT $\beta$ R signaling is also important in the maturation step, as well as the in situ survival of lymphoid cells. For example, the interaction between LT $\beta R$ on bone marrow (bm) stromal cells and LT on NK cells is an important step in early NK cell development. Furthermore, survival signals via LT $\beta$ R activation protect lymphocytes from apoptosis, for instance during virus infection. ${ }^{13}$ Hence, LT $\beta$ R signaling clearly plays a role in the control of local inflammatory reactions via lymphocyte attraction, maturation and survival.

Given that LT $\beta$ R and its ligands are involved in lymphoid structure formation, which continues to develop in early life, ${ }^{14-16}$ we generated bm chimeras with neonatal or adult mice to compare the effect of LT $\beta R$ signaling during maturation. Neonatal transplantation of human haematopoietic stem cells is commonly used in the generation of 'humanized' mice, and displayed high transplantation efficiency when transplanted into the liver of newborn mice. ${ }^{17,18}$

To elucidate the importance of LT $\beta R$ signaling in the control of inflammatory processes, these mice chimeras were subjected to DSS-induced colitis, which represents a model of inflammatory bowel disease (IBD). IBD comprises different chronic or recurring immune response, and inflammation of the gastrointestinal tract. The main forms of IBD are Crohn's disease and ulcerative colitis, which can trigger the development of colorectal cancer and limit the quality of life in general. The etiology of IBD is still unknown and, therefore, the only available treatments focus on unspecific immunosuppression. In colitis, the role of LT function has been shown to be as important as the TNF- $\alpha$ signaling for disease development and maintenance. Therefore, understanding the role of activation of the LT $\beta R$ during this inflammatory disorder might lead to the development of more specific treatment schedules with reduced side effects.

\section{Materials and methods}

\section{Animal husbandry}

Mice used in all experiments were housed under specific pathogen-free conditions in the animal facility of the University of Regensburg, Regensburg, Germany, and regularly monitored for the absence of specific pathogens, as recommended by the Federation of Laboratory Animal Science Associations.

\section{Bm chimeras}

$\mathrm{Bm}$ cells were isolated from femur, tibia and humerus of donor mice $\left[\mathrm{C} 57 \mathrm{Bl} / 6, \mathrm{LT} \beta \mathrm{R}^{-/}\right.$and $\mathrm{C} 57 \mathrm{Bl} / 6$ mice congenic for CD45.1 (Ly5.1)] flushed out with cold PBS, filtered through a $40-\mu \mathrm{m}$ nylon cell strainer and centrifuged at $300 \mathrm{~g}$ at $4^{\circ} \mathrm{C}$ for $10 \mathrm{~min}$. Neonatal transplantations were performed by intrahepatic injection of $3 \times 10^{7}$ bm cells into $24-48$-h-old mice $3 \mathrm{~h}$ after 5-gray (Gy) radiation. Eight wks post-transplantation reconstitution levels of the donor cells were analyzed in the peripheral blood by flow cytometry.

Adult transplantation was performed by injection of $6 \times 10^{6} \mathrm{bm}$ cells intravenously in mice at $8-10 \mathrm{wks}$ of age following two doses of 5-Gy radiation. Three and 6 wks post-transplantation peripheral blood was obtained and analyzed for reconstitution levels of donor cells as described for neonatal transplanted mice. A total of 35 neonatal and 29 adult transplanted chimeras were generated, and 30 (neonatal) and 29 (adult) mice used for colitis experiments.

\section{DSS-induced colitis}

Acute colitis was induced in all chimeras by addition of $3 \%$ DSS MP Biochemical (Solon, Ohio, USA) to the drinking water for a period of $7 \mathrm{~d}$.

The animals' mass and general conditions were monitored on a daily basis. On d 7, animals were sacrificed and all organs were harvested for myeloperoxidase (MPO), histology and single cell analyses in flow cytometry.

\section{Disease score}

Mice undergoing DSS treatment were monitored daily and finally histology was performed $7 \mathrm{~d}$ after the beginning of treatment to determine the disease score. The classification of each individual mouse was conducted as described in Table 1.

\section{MPO}

To measure neutrophilic granulocyte infiltration tissue, samples from the middle part of the colon were harvested and prepared as described previously. ${ }^{12}$ Briefly, tissue samples were placed in a solution of potassium phosphate buffer $(50 \mathrm{mmol} / \mathrm{l}, \mathrm{pH} 6.0)$ containing $0.5 \% \quad(\mathrm{w} / \mathrm{v})$ hexadecyltrimethylammonium bromide $(1 \mathrm{ml} / 30 \mathrm{mg}$ tissue). After homogenization

Table I. Disease score.

\begin{tabular}{ll}
\hline Score & Description \\
\hline 0 & No disease + no diarrhea \\
1 & Low-grade diarrhea \\
2 & High-grade diarrhea \\
+1 & Bloody diarrhea \\
+1 & Bad general condition \\
+1 & Death during experiment \\
\hline
\end{tabular}


(Ultra Turrax; IKA Labortechnik, Staufen, Germany), samples were frozen and thawed three times, centrifuged at $44,000 \mathrm{~g}$ at $4^{\circ} \mathrm{C}$ for $20 \mathrm{~min}$, and $10 \mu \mathrm{l}$ of the supernatants were transferred into phosphate buffer $(\mathrm{pH} \quad 6.0) \quad$ containing $\quad 0.17 \mathrm{mg} / \mathrm{ml} \quad 3,3^{\prime}$-dimethoxybenzidine and $0.0005 \%$ hydrogen peroxide $\left(\mathrm{H}_{2} \mathrm{O}_{2}\right)$. The $\mathrm{H}_{2} \mathrm{O}_{2}$-dependent oxidation of 3,3'-dimethoxybenzidine was measured for MPO activity.

\section{Single cell isolation from different organs}

Single cells were isolated from peripheral blood and from different mouse tissues, such as spleen, lymph nodes and bm, as described previously. ${ }^{19}$ Briefly, spleen and lymph nodes were cut into small pieces and pressed through a $40-\mu \mathrm{m}$ nylon filter using the plunger of a $2 \mathrm{ml}$ syringe. Cells were washed with PBS supplemented with 5\% FCS and centrifuged at $300 \mathrm{~g}$ at $4^{\circ} \mathrm{C}$ for $10 \mathrm{~min}$. For bm cells, femurs were collected, both ends were clipped off and cells flushed out with PBS using a $25-\mathrm{G}$ needle, filtered through a $40-\mu \mathrm{m}$ nylon cell strainer and centrifuged at $300 \mathrm{~g}$ at $4{ }^{\circ} \mathrm{C}$ for $10 \mathrm{~min}$.

\section{Flow cytometry}

Reconstitution levels of donor cells in peripheral blood were determined using CD45.1 phycoerythrin (PE) (clone A20; Becton-Dickinson (BD) Biosciences (San Jose, CA, USA)) and CD45.2 FITC-conjugated Abs (clone 104; eBioscience) together with anti-CD3 APC or Percp-Cy5.5 (clone 145-2C11; eBioscience) and antiB220 Percp-Cy5.5 (clone RA3-6B2; eBioscience (San Diego, CA, USA)). Samples were further analyzed using the following $\mathrm{mAb}$ from $\mathrm{BD}$ Bioscience (San Diego, CA, USA): anti-Ly6C FITC or biotin (clone $\mathrm{Al}-21$ ), anti-Ly6G PE (clone 1A8), and anti-CD11b FITC (clone M1/70). The following Abs from eBioscience were used in addition: anti-Gr-1 APC (clone RB6-8C5); anti-CD11c Alexa700 (clone N418); anti-F480 Pacific Blue (clone BM8). For detection of LT $\beta$ R-expressing cells, anti-LT $\beta$ R biotin (clone 3C8) from eBioscience was used. All samples were analyzed using a FACSLSR II flow cytometer with the Diva software package Becton-Dickinson (BD) Biosciences (San Jose, CA, USA). To reduce non-specific binding of $\mathrm{mAb}$, cells were incubated with anti-mouse Fc receptor Abs $(10 \mu \mathrm{g} / \mathrm{ml}$; Sigma-Aldrich (Sigma-Aldrich, Taufkirchen, Germany)) on ice for 20 min before staining with specific $\mathrm{mAb}$ or isotype control $\mathrm{mAb}$.

\section{Histology}

Animals were sacrificed by cervical dislocation. Colons were isolated, measured for length and flushed with sterile PBS. Distal colon sections were fixed in 4\% neutral buffered formalin, and $4-\mu \mathrm{m}$ paraffin sections were
Table 2. Histological score.

\begin{tabular}{|c|c|c|}
\hline Score & $\begin{array}{l}\text { Epithelial } \\
\text { damage }\end{array}$ & Inflammatory infiltration \\
\hline 0 & None & None \\
\hline I & None & Infrequent \\
\hline 2 & None & $\begin{array}{l}\text { Between crypts and lamina musc. } \\
\text { mucosae (mild) }\end{array}$ \\
\hline 3 & $\begin{array}{l}\text { Partial loss } \\
\text { of crypts }\end{array}$ & Moderate $(+$ edema) \\
\hline 4 & $\begin{array}{l}\text { Extensive loss } \\
\text { of crypts }\end{array}$ & $\begin{array}{l}\text { Between lamina musc. mucosae and } \\
\text { submucosa (massive, extensive) }\end{array}$ \\
\hline
\end{tabular}

Musc.: lamina muscularis mucosae.

prepared. Specimens were de-paraffinized and pretreated by microwave heating for $30 \mathrm{~min}$ at $320 \mathrm{~W}$ in

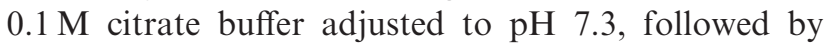
hematoxylin and eosin (H\&E) staining and histological evaluation for colonic damage, as described in Table 2.

\section{Statistics}

Statistical analysis was performed using GraphPad's Prism software (GraphPad, La Jolla, CA, USA). A Student's $t$-test was applied for MPO, colon length and flow cytometric data. Two-way ANOVA+ Bonferroni post-test were used for weight loss analyses, and a Mann-Whitney rank sum test was employed for histological score, disease score and colon length. Significance was set at $P>0.05$.

\section{Results}

\section{$\mathrm{Bm}$ transplantation of adult, as well as of neonatal,} mice led to high reconstitution levels in all organs, but did not influence lymphoid structure formation

To elucidate the effect of LT $\beta$ R signaling during hematopoiesis in a growing organism, we compared two different bm cell transplantation models in this study: one transplantation method using adult mice (aged 8-10 wks) and a transplantation model using neonatal mice (aged 24-48 h). Thus, we were able to compare the influence of transplantation on immune cell differentiation at an early stage of hematopoiesis with the adult model. Importantly, both transplantation methods revealed equally high reconstitution levels in all tissues, including the peripheral blood, the bm, the spleen and lymph nodes, independent of the time point of transplantation (neonatal: Figure 1a; adult: Supplementary Figure 1a). In both setups, reconstitution was stable for more than $1 \mathrm{yr}$, but neonatal transplantation resulted in decelerated growth of the animals owing to the irradiation dose of $5 \mathrm{~Gy}$. Nevertheless, lymphoid structure formation could not be rescued by the wild type (wt) bm transplantation in $\mathrm{LTBR}^{-/-}$neonatal mice as only one out of 13 transplanted neonatal $\mathrm{LTBR}^{-/-}$mice 


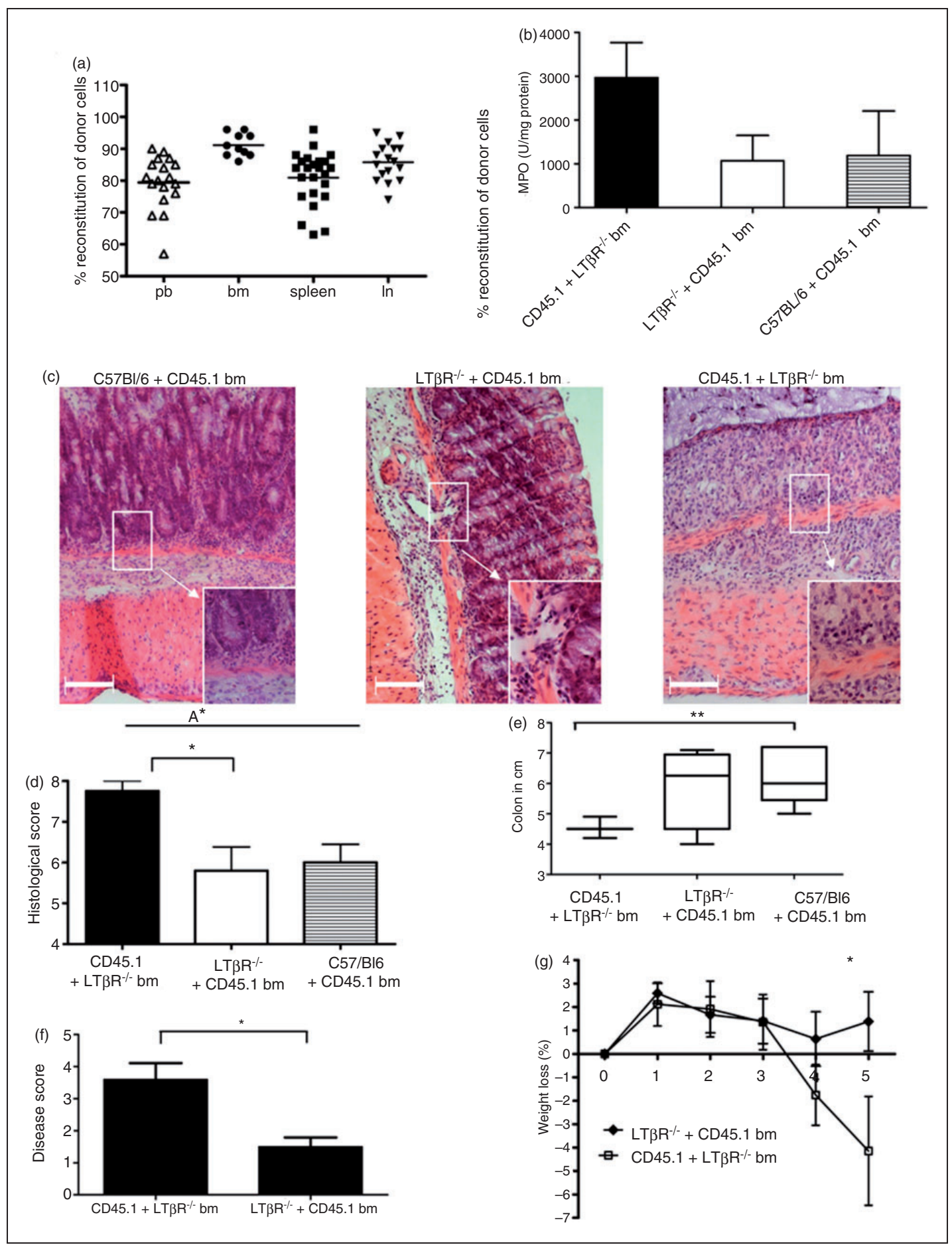

Figure I. LT $\beta \mathrm{R}^{-1-}$ bm-transplanted chimeras revealed aggravated signs of inflammation and tissue damage after DSS colitis. (a) Flow cytometry of peripheral blood $(\mathrm{pb})$ of bm reconstituted mice (neonatal transplantation; 14 wks post-transplant) analyzed by the expression of the congenic markers Ly5.I (CD45.I) in C57BI/6 and LT $\beta R^{-1-}$ mice, and Ly5.2 (CD45.2) in CD45.I mice. Inflammation and tissue damage after DSS-induced colitis were measured as MPO activity (b) in U/mg of protein isolated from the distal part of the colon; histological score (d) representing mucosal damage and inflammatory infiltrates, as described in Table 2; and reduction of colon length (e) as a marker of injury measured in $\mathrm{cm}$ of colon. (f) Mass was monitored daily during DSS treatment, and disease score (g) was assessed on the day of sacrificing the animals (Table I). (c) Representative H\&E-stained colon section of C57BI/6 mice transplanted with CD45.I bm, LT $\beta R^{-1-}$ mice transplanted with CD45.I bm and CD45.I mice transplanted with $\mathrm{LT}^{-1} \mathrm{R}^{-1-}$ bm. Bars represent $100 \mu \mathrm{m}$. Data were analyzed using Student's $t$-test (MPO, colon length), one-way ANOVA $\left(A^{*}=P<0.05\right)+$ Tukey's multiple comparison test (histological score, MPO) and two-way-ANOVA + Bonferroni post-test (mass loss). Error bars represent means \pm SEM. $* P<0.05)$, $* * P<0.0$ I). In: lymph nodes. 
developed mesenteric lymph nodes. These findings have also been observed in adult transplantation in $\mathrm{LTBR}^{-1-}$ mice, which did not result in lymph node formation $(0 / 9)$. All other transplanted groups (including neonatal wt mice transplanted with $\mathrm{LTBR}^{-1-} \mathrm{bm}$ ) developed mesenteric lymph nodes (even; data not shown).

\section{Chimeras transplanted with LT $\beta R$-deficient bm cells developed exacerbated inflammatory reactions in DSS-induced colitis}

After $7 \mathrm{~d}$ of DSS treatment, mice transplanted with $\mathrm{LT} \mathrm{R}^{-1-}$ bm cells demonstrated (a) MPO activity, indicating granulocyte influx into the tissue (Figure 1b, Supplementary Figure 1B) and (b) the most serious tissue damage, including loss of crypts, severe inflammatory infiltrates and loss of mucosal architecture (Figure 1c), resulting in an increased histological score (Figure 1d) in both transplantation models. In addition, the reduction of colon length as a result of on-going inflammation was much more pronounced in mice lacking LT $\beta$ R on hematopoietic cells than in mice lacking LT $\beta$ R expression on stromal cells (Figure 1e, Supplementary Figure 1C). Both transplantation strategies revealed a significant worsening of disease and mass loss when bm cells lacked LT $\beta R$ expression (Figure 1f, g, Supplementary Figure 1D, E). Thus, in both models LTBR deficiency led to an exacerbation of the inflammatory response upon DSS and therefore supports the earlier finding that LT $\beta$ R signaling on hematopoietic cells (and not on stromal cells) down-regulates exaggerated inflammation in a model of acute DSS-induced colitis. ${ }^{6}$ This result was independent of whether the bm transplantation occurred in neonatal or adult animals.

\section{Myeloid cell proportion increased in peripheral blood after DSS-induced colitis}

Peripheral blood of neonatally-transplanted chimeras was analyzed by flow cytometry 6,10 and 14 wks after bm transfer. The results show an increase of B cells (Figure 2a) in parallel with a slight decrease of $\mathrm{T}$ cells (Figure 2b) and myeloid cells (CD33 ${ }^{+}$; Figure 2c), independently of whether mice were transplanted with $\mathrm{LT} \mathrm{R}^{-/-}$or $\mathrm{LT} \beta \mathrm{R}^{+/+}$bm cells. Such changes in the lymphocyte composition were not observed in adult transplanted animals (data not shown), which already had a solid B cell population 2 wks post-transplantation.

In both adult and neonatal chimera models an equal change in cell composition was found after $7 \mathrm{~d}$ of DSStreatment characterized by a significant decrease of the B cell fraction (Figure 2a) paralleled by a significant increase of the myeloid cell fraction (Figure 2c). Further characterization of the myeloid cells revealed that these cells were positive for CD11c. The proportion of these $\mathrm{CD} 11 \mathrm{c}^{+}$cells (Figure 2d) was similar in both types of chimeras and independent of LT $\beta R$ expression. Two different myeloid cell populations were found. The larger fraction was characterized by the markers $\mathrm{CD}_{11 \mathrm{c}^{+}} \mathrm{Grl}^{+} \mathrm{Ly}^{+} \mathrm{C}^{+}$(Figure 2e) and located in the forward scatter (FSC)/side scatter (SSC) area of granulocytic cells (Figure 2f, top arrow). The smaller fraction with the profile of $\mathrm{CD} 11 \mathrm{c}^{+} \mathrm{Gr}^{-}$ Ly6C $\mathrm{C}^{+}$cells (Figure 2f, bottom arrow, Figure 2g) was slightly higher in animals transplanted with $\mathrm{LT} \mathrm{R}^{-/-} \mathrm{bm}$.

\section{Maturation of different splenic myeloid cell population in mice transplanted neonatally with $L T \beta R^{-1-}$ bm}

Spleen cells serve as a reservoir for inflammatory monocytes during inflammation, and extra-medullary proliferation of myeloid cells contributes massively to the monocytic cell pool under inflammatory conditions. Therefore, we further characterized different subsets of myloid cells in this lymphoid organ by flow cytometry (Figure 3), including macrophages (F480), DCs (CD11c) and their subpopulations. Animals transplanted with LT $\beta \mathrm{R}^{-/-}$bm cells showed a significantly lower percentage of macrophages (Figure 3d, left), but a higher proportion of $\mathrm{CD} 11 \mathrm{c}^{+}$cells (Figure $3 \mathrm{~d}$, second graph). In all chimeras the predominant population of $\mathrm{F} 480^{+}$macrophages was $\mathrm{F} 480^{+} \mathrm{CD} 11 \mathrm{c}^{-} \mathrm{Gr}^{+} \mathrm{Ly}^{-} \mathrm{C}^{-}$(data not shown). In contrast, the majority of $\mathrm{CD} 11 \mathrm{c}^{+}$cells were $\mathrm{Ly}_{6 \mathrm{c}}{ }^{++} \mathrm{GR}^{++}$(Figure 3d, third graph), and were located in the FSC/SSC area of granulocytes.

Chimeras that had received $\mathrm{LT} \beta \mathrm{R}^{-1-}$ bm cells showed a reduced proportion of immature $\left(\mathrm{F} 480^{+}\right.$ $\mathrm{Grl}^{+} \mathrm{CD} 1 \mathrm{c}^{-} \mathrm{Ly}_{6} \mathrm{C}^{-}$) monocytic cells in the spleen, independent of whether they had been transplanted as neonates or adults (data not shown).

Significant differences in myeloid subpopulation generation after DSS colitis were observed within a subset of Ly $6 \mathrm{c}^{++} \mathrm{Gr}^{-}$cells. This population was significantly more reduced in adult and neonatal mice transplanted with LT $\beta R$-deficient hematopoietic cells (Figure 3d, right graph). These cells could neither be assigned to the population of mature $\mathrm{DC}\left(\mathrm{CD} 11 \mathrm{c}^{+}\right)$nor to macrophages $\left(\mathrm{F}_{480^{+}}\right)$. Therefore, we also stained for $\mathrm{CD} 11 \mathrm{~b}$, which enables the separation of $\mathrm{CD} 11 \mathrm{~b}^{+}$ $\mathrm{Ly}_{6 \mathrm{c}^{+}} \mathrm{Ly}_{6 \mathrm{G}}{ }^{+}$immature granulocytic and $\mathrm{CD} 11 \mathrm{~b}^{+}$ Ly6c $\mathrm{c}^{+}$Ly6G ${ }^{-}$immature monocytic populations (Figure 3e, first and second graph). Both of these subsets of immature myeloid cells were reduced in the blood and spleens of mice transplanted with $\mathrm{LT}_{\beta} \mathrm{R}^{-1-}$ bm cells (Figure 3e).

Taken together, the lack of LT $\beta R$ expression on hematopoietic cells induced a slight shift from mature macrophages toward DC and granulocytes. In addition, a reduced proportion of immature myeloid cells in mice transplanted with LT $\beta R$-deficient bm was observed in the spleen and in the peripheral blood (Figure 3e). 


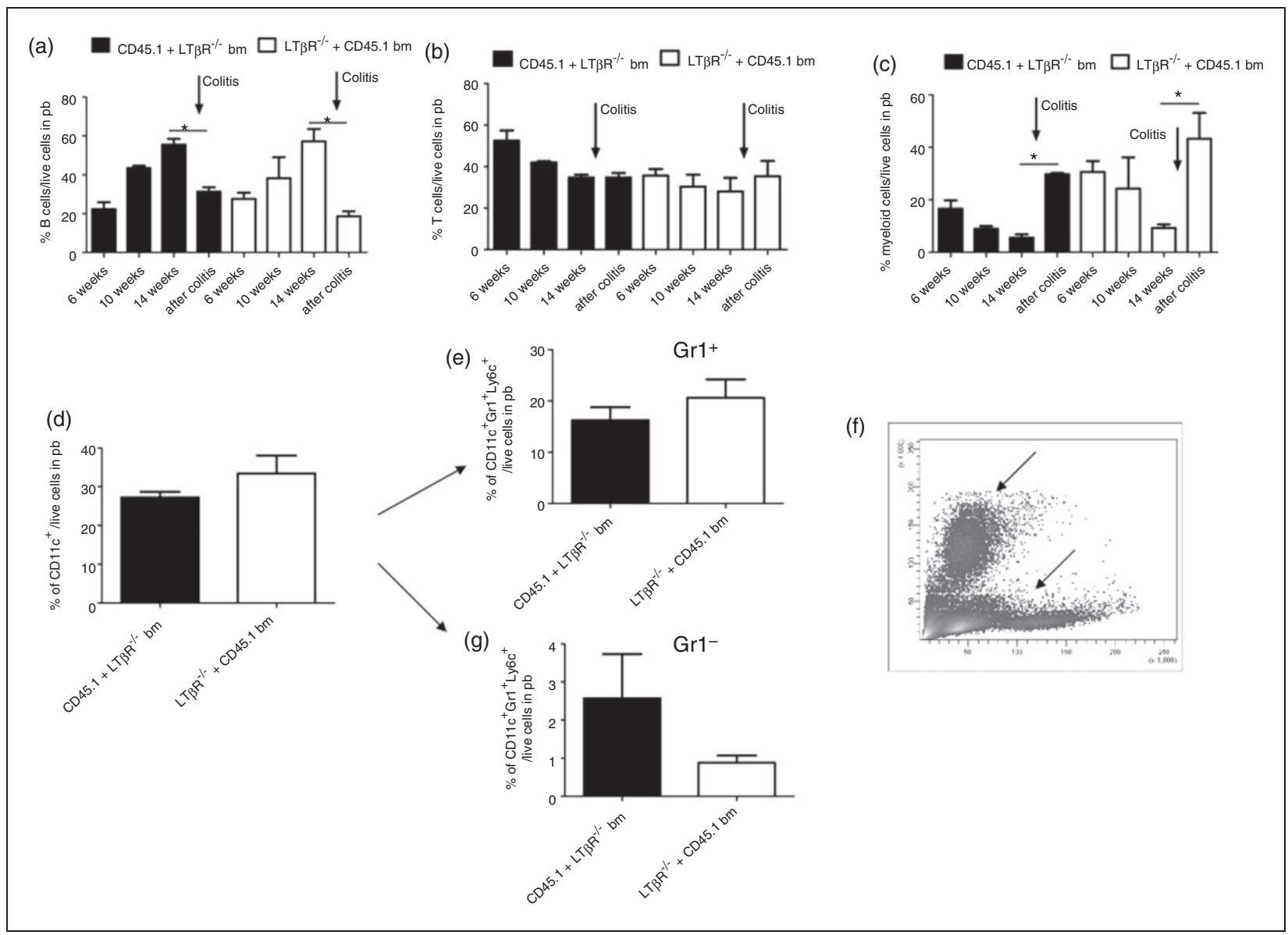

Figure 2. Cell composition in peripheral blood changes after DSS-induced colitis in all chimeras. Peripheral blood (pb) analyses of B cells (a), T cells (b) and myeloid cells (c) in neonatal-transplanted chimeras 6, 10 and I4 wks post-transplant (without colitis) and at $\mathrm{d} 7$ after DSS-induced colitis (arrow). Chimeras [CD45.I bm in LT $\beta R^{-1-}$ mice $(n=4)$, LT $\beta R^{-1-}$ bm in CD45.I mice $\left.(n=5)\right]$ were analyzed for $\mathrm{CDIIc}^{+}$cells (d) and their subsets $\mathrm{CDIIc}{ }^{+} \mathrm{Grl}^{+} \mathrm{Ly}_{6 c^{+}}(\mathrm{E})$ and $\mathrm{CDIIc}{ }^{+} \mathrm{Grl}^{-} \mathrm{Ly}_{6 c^{+}}(\mathrm{g})$. (f) Density plot of peripheral blood showing two cell populations (indicated by arrows) that were increased after DSS colitis. Error bars represent means \pm SEM. Data were analyzed using Student's t-test. $* P<0.05)$.

Of note, no significant differences in $\mathrm{T}$ and $\mathrm{B}$ cell proportion were detected in the spleen or the peripheral blood of any chimeras after DSS-induced colitis (data not shown).

\section{Characterization of myeloid subpopulation expressing $L T \beta R$ in peripheral blood, spleen and lymph node after DSS-induced colitis}

Chimeras that had been transplanted with bm cells from wt mice were analyzed for their LT $\beta$ R expression profile on hematopoietic cells. In peripheral blood, two different cell populations were positive for LT $\beta R$ staining (Figure $4 \mathrm{a}, \mathrm{b}$ ). One population was characterized by $\mathrm{F}_{480}{ }^{+} \mathrm{CD} 11 \mathrm{c}^{-}$(Figure 4a, fourth graph) consisting of Ly6C-negative and Ly6C-positive cells (Figure 4a, fifth graph). The other population in peripheral blood (Figure 4b) and the $\mathrm{LT} \mathrm{R}^{+}$populations in the spleen (Figure 4c) did not express CD11c, F480 or GR-1, but some cells displayed a high expression of Ly6C. Of note, this CD11c- and F480-negative myeloid cell subpopulation, which had the marker profile typical for immature monocytic inflammatory, or so-called 'suppressor' cells, was significantly reduced in mice that had been transplanted with $\mathrm{LT} \beta \mathrm{R}^{-/-}$bm cells (Figure 3d, fourth graph). Only a few LT $\beta$ Rexpressing cells were detectable in the lymph nodes, mainly without expression of any of the tested markers (Figure 4d).

\section{Discussion}

LT $\beta$ R and its activation by the ligands LIGHT, LT $\alpha 3$ and LT $\alpha 1 \beta 2$ are involved in many immunologic processes, including immune cell induction, activation and recruitment, as well as lymphoid structure formation. The important role of LT $\beta$ R signaling in the DSS colitis model was described previously and showed an enhanced inflammatory reaction when LT $\beta$ R signaling is blocked. ${ }^{4-6}$

Because the LT system is involved in the development and maintenance of lymphoid structures in 


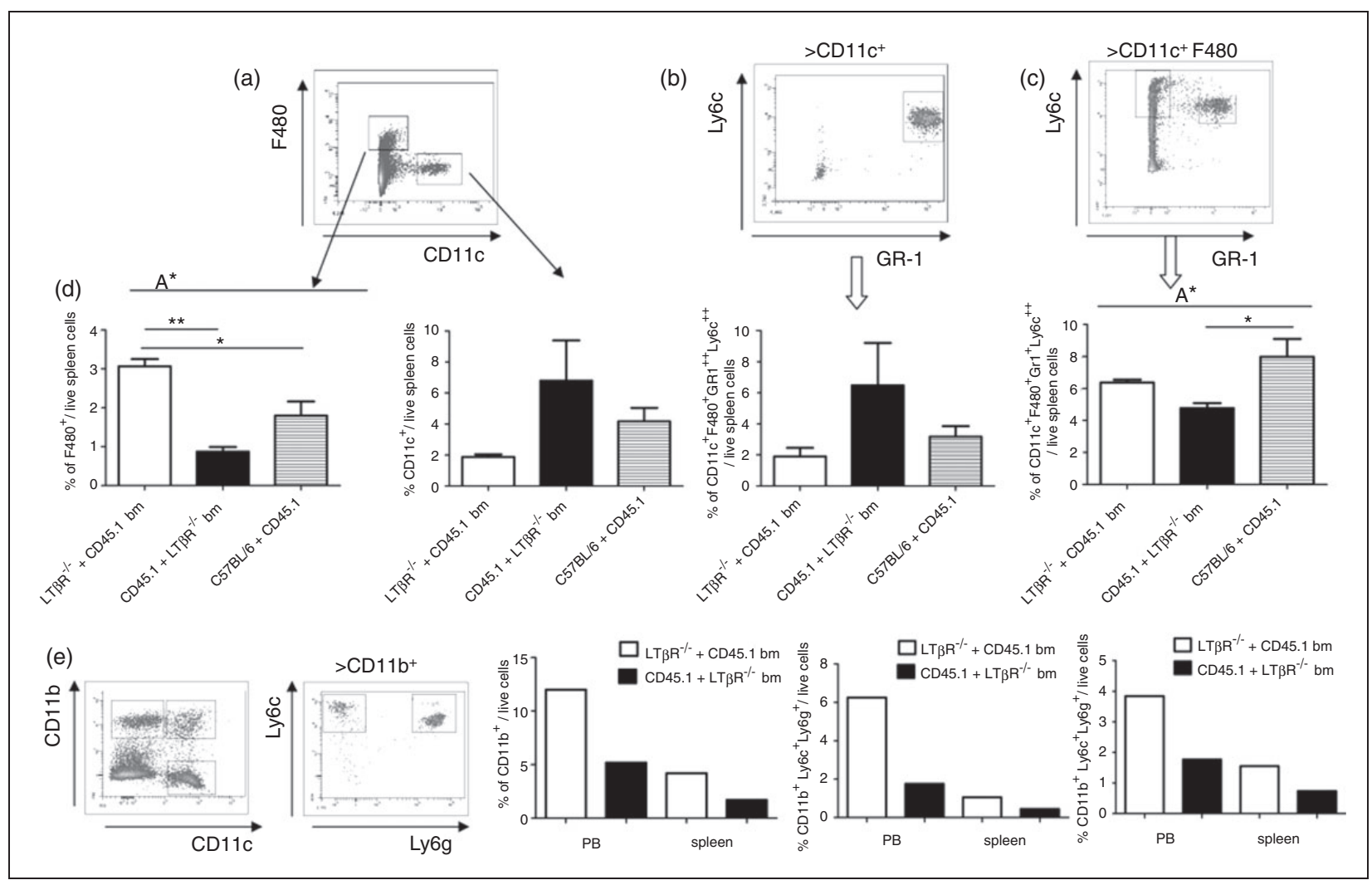

Figure 3. Characterization of myeloid subpopulations in different chimera subsets after DSS-induced colitis. Density plots showing gating strategies for $\mathrm{F}_{480^{+}}$and $\mathrm{CDIIc}{ }^{+}$cells (a) gated on live cells, $\mathrm{Ly}_{6 \mathrm{c}}{ }^{+}$and $\mathrm{GrI}^{+}$of $\mathrm{CDIIc}{ }^{+}$cells (b), and $\mathrm{Ly} 6 \mathrm{c}^{++}$and $\mathrm{Grl} \mathrm{I}^{+}$of $\mathrm{CDI} \mathrm{Ic}{ }^{-} \mathrm{F}_{480^{-}}$cells (c). GraphPad Prism illustration of spleen cells separated from neonatal-transplanted chimeras after DSS-induced colitis (d) showing differences of myeloid cell fractions in mice transplanted with $\mathrm{LT} \beta \mathrm{R}^{-/-} \mathrm{bm}$ in the population of F480 $0^{+}$cells (first

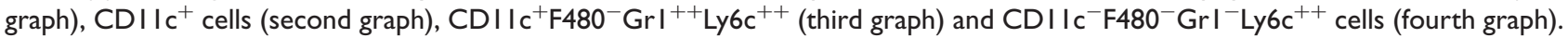
(e) Dot plots representing CDI Ib ${ }^{+}$and $\mathrm{CDI} \mathrm{Ic}^{+}$populations of live cells (first plot), and Ly6g and Ly6c on CDI I b ${ }^{+}$cells (second plot) in peripheral blood (PB). Graphs of pooled mice samples $(n=3)$ from peripheral blood and spleen of CD45.I mice transplanted with $\mathrm{LT}_{\beta} \mathrm{R}^{-1-} \mathrm{bm}$ and CD45.I mice transplanted with C57BI/6 bm. Graphs represent the percentage of CDI Ib cells (left graph),

$\mathrm{CDIIb}{ }^{+} \mathrm{Ly}_{6 \mathrm{c}}{ }^{+} \mathrm{Ly}_{6 \mathrm{~g}}{ }^{+}$and $\mathrm{CDII} \mathrm{Ib}{ }^{+} \mathrm{Ly}_{6 \mathrm{c}}{ }^{++} \mathrm{Ly}_{6 \mathrm{~g}}{ }^{-}$of live cells (right graph). Error bars represent means \pm SEM. Data were analyzed using one-way ANOVA $\left(A^{*}=P<0.05\right)$ and Tukey's multiple comparison test. $\left.* P<0.05\right), * * P<0.01$.

general, ${ }^{1-3}$ and at the mucosal site of gut-associated lymphoid tissue, in particular, ${ }^{20}$ we used two transplantation models (neonatal and adult transplantation) to determine whether the expression of LT $\beta$ R at different time points during hematopoiesis influences disease progression later in life.

Interestingly, both transplantation strategies resulted in very similar findings: wt bm transplantation in $\mathrm{LTBR}^{-1-}$ mice was not able to rescue lymphoid structure formation, even when transplanted in newborn mice. Therefore, lymphoid structure formation is dependent on LTBR expression on stromal cells and not on hematopoietic cells. The lack of mesenteric lymph node formation in the $\mathrm{LTBR}^{-/-}$recipients does not seem to hinder acute inflammation processes in the gut. $\mathrm{LTBR}^{-/-}$and control mice (wt $+\mathrm{wt} \mathrm{bm}$ ) demonstrated comparable immune response, shown cumulatively by a similar inflammation profile, MPO activity, histological score and colon length. Furthermore, it has been previously reported that extra-lymphoid tissues play an important role in the induction of immune responses. ${ }^{21,22}$ In addition, $\mathrm{LTBR}^{-1-}$ mice revealed similar allograft rejection as wt mice, but this graft-versus-host disease (GvHD) reaction was delayed in splenectomized $\mathrm{LT}_{\beta} \mathrm{R}^{-/-}$ mice. ${ }^{23}$ Therefore, immune activation, which usually occurs in the peripheral lymph nodes, can be compensated for by the spleen in $\mathrm{LTBR}^{-/}$animals. Nevertheless, the influence of missing lymph nodes in $\mathrm{LTBR}^{-/-}$mice during DSS-induced colitis cannot be excluded completely.

During DSS-induced colitis, the lack of LT $\beta$ R on hematopoietic, but not on stromal, cells led to an increase in inflammation and tissue damage, which was clearly demonstrated by the very high inflammatory cell influx and MPO activity. These results indicate that activation of the LT $\beta$ R on hematopoietic and not on stromal cells is essential for restraining the inflammation. Thus, LT $\beta$ R expression on hematopoietic cells seems to be important to dampen on-going 


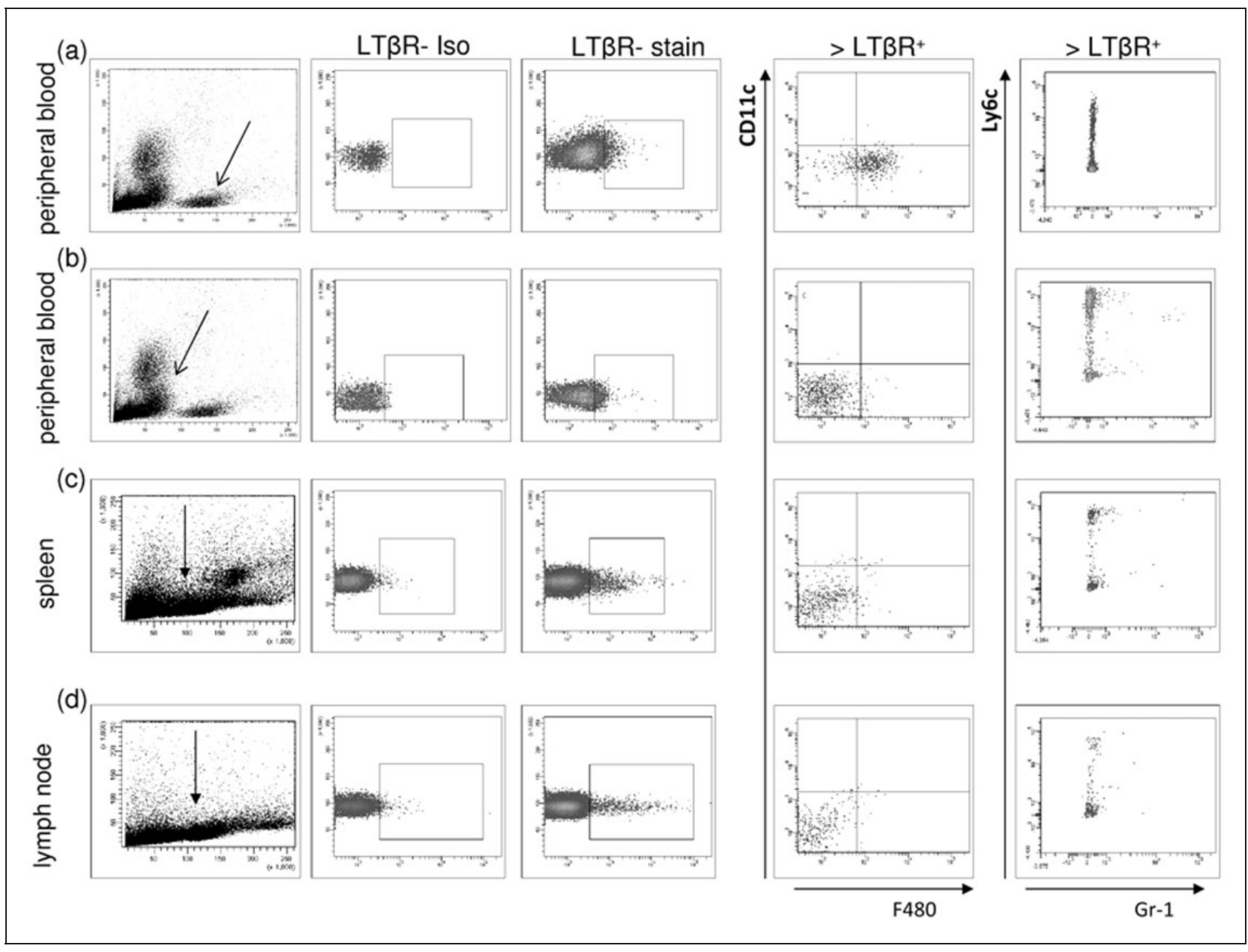

Figure 4. LT $\beta$ R expression on different cell populations in peripheral blood, spleen and lymph node after DSS-induced colitis. (a-d first plot) Morphology plot of peripheral blood, spleen and lymph node of chimeras transplanted with wt bm. The second and third plots display isotype and LT $\beta$ R staining of gated live cells from the population indicated in the morphology plot (arrows). Third (and fourth) plot outlines CDI Ic and F480 (and Ly6c and Gr, respectively) expression profile of LT $\beta R^{+}$cells.

inflammation, and to block the recruitment and proliferation of inflammatory cells in the tissue.

Characterization of different peripheral blood subpopulations after DSS-colitis showed an LT $\beta$ R-independent significant reduction of B cells and increase of myeloid cells. The main subpopulation of the increased myeloid cell fraction in all chimeras were characterized as granulocytes $\left(\mathrm{CD} 11 \mathrm{c}^{+} \mathrm{Gr} 1^{+} \mathrm{Ly} 6 \mathrm{C}^{+}\right)$, which also entered the intestinal area, as indicated by the MPO activity.

Because $\mathrm{LT} \beta \mathrm{R}^{-1-}$ mice do not generate lymph nodes, we analyzed spleens as lymphoid organs to look for differences in the hematopoietic cell fraction. None of the chimeras showed significant variations in the splenic B and T cell fractions. However, differences in the myeloid cell fraction were found. Chimeras (adult and neonatal transplanted) that lacked LT $\beta R$ on hematopoietic cells showed significantly fewer macrophages, and a significantly reduced myeloid cell population, which lacked F480, CD11c and Gr1 markers, but expressed Ly6C. Interestingly, this population of immature myeloid inflammatory cells was also partly positive for LT $\beta R$ expression in blood, spleen and lymph nodes in chimeras transplanted with wt bm.

We further characterized this fraction as $\mathrm{CD} 11 \mathrm{~b}^{+}$ cells being either Ly6C- and Ly6G-positive or Ly6C $\mathrm{C}^{\text {high }}$ Ly6G-negative. Both cell populations were reduced in chimeras transplanted with $\mathrm{LT} \beta \mathrm{R}^{-/-} \mathrm{bm}$. These subsets of $\mathrm{CD}_{11 \mathrm{~b}^{+}}$cells are also described as immature granulocytic or monocytic cells, respectively. They belong to the immature myeloid cell lineage with immunosuppressive functions [myeloid-derived suppressor cells (MDSC)] and were decreased in chimeras without LT $\beta R$ on hematopoietic cells.

Such suppressive immature cells represent a heterogeneous population ${ }^{24-27}$ with multiple immunosuppressive functions ${ }^{27-33}$ and have been described in tumors, ${ }^{25,34-36}$ infection, ${ }^{37-39}$ and during $\mathrm{GvHD}^{40}$ and auto-immune encephalitis. ${ }^{41}$ Importantly, these cells were also involved in the regulation of IBD by inhibiting $\mathrm{T}$ cell-mediated intestinal injury. ${ }^{42}$ 
The highest degree of intestinal inflammation in our chimeras reconstituted with $\mathrm{LT} \beta \mathrm{R}^{-1-}$ bm was seen in mice where such immature myeloid cells were reduced. Interestingly, this myeloid subpopulation expressed LT $\beta R$ in wt chimeras. Therefore, LT $\beta R$ expression on hematopoietic cells might be involved in induction or recruitment of immature myeloid cells in colitis, resulting in amelioration of inflammation.

\section{Conclusions}

In conclusion, our experiments indicate that activation of the LT $\beta R$ could play a role in the induction or recruitment of myeloid suppressor cells in inflammatory processes. The results of the present study demonstrate that LTBR expression on stromal cells is essential for lymph node formation, whereas the regulation of inflammation is controlled by LTBR expression on hematopoietic cells. In addition, the maturation of myeloid subpopulation is also influenced by LTBR expression, and lack of this receptor results in an increased proportion of DCs, and reduced proportion of macrophages and myeloid progenitor cells (MDSCs).

\section{Funding}

This work was supported by the Deutsche Forschungsgemeinschaft (grant number: HE3116/8 to TH).

\section{Conflict of interest}

The authors do not have any potential conflicts of interest to declare.

\section{Acknowledgements}

We especially thank Dr Nancie Archin (University of North Carolina at Chapel Hill School of Medicine, USA) for proofreading the manuscript. We thank Prof. O. Kölbl (Department of Radiotherapy, University of Regensburg) for providing access to the linear accelerators for irradiation. We would like to thank M. Bock and K. Holz for excellent technical assistance, and Prof. G. Brockhoff (Clinic of Gynecology and Obstetrics, University of Regensburg) for the excellent graphic design of the figures.

\section{References}

1. De Togni P, Goellner J, Ruddle NH, Streeter PR, Fick A, Mariathasan S, et al. Abnormal development of peripheral lymphoid organs in mice deficient in lymphotoxin. Science 1994; 264 : 703-707.

2. Banks TA, Rouse BT, Kerley MK, Blair PJ, Godfrey VL, Kuklin NA, et al. Lymphotoxin-deficient mice: effects on secondary lymphoid organ development and humoral immune responsiveness. J Immunol 1995; 155: 1685-1693.

3. Futterer A, Mink K, Luz A, Kosco-Vilbois MH and Pfeffer K. The lymphotoxin $\beta$ receptor controls organigenesis and affinity maturation in peripheral lymphoid tissues. Immunity 1998; 9: 59-70.

4. Stopfer P, Mannel DN and Hehlgans T. Lymphotoxin-beta receptor activation by activated $\mathrm{T}$ cells induces cytokine release from mouse bone marrow-derived mast cells. Immunol 2004; 172: 7459-7465.
5. Jungbeck M, Stopfer P, Bataille F, Nedospasov SA, Männel DN and Hehlgans T. Blocking lymphotoxin beta receptor signalling exacerbates acute DSS-induced intestinal inflammation-opposite functions for surface lymphotoxin expressed by $\mathrm{T}$ and B lymphocytes. Mol Immunol 2008; 45: 34-41.

6. Wimmer N, Huber B, Wege AK, Barabas N, Röhrl J, Pfeffer K and Hehlgans T. Lymphotoxin-beta receptor activation on macrophages ameliorates acute DSS-induced intestinal inflammation in a TRIM30 $\alpha$-dependent manner. Mol Immunol 2012; 51: $128-135$.

7. Newberry RD, McDonough JS, McDonald KG and Lorenz RG. Postgestational lymphotoxin/lymphotoxin beta receptor interactions are essential for the presence of intestinal B lymphocytes. J Immunol 2002; 168: 4988-4997.

8. Kabashima K, Banks TA, Ansel KM, Lu TT, Ware CF and Cyster JG. Intrinsic lymphotoxin-beta receptor requirement for homeostasis of lymphoid tissue dendritic cells. Immunity 2005; 22: 439-450.

9. Abe K, Yarovinsky FO, Murakami T, Shakhov AN, Tumanov $\mathrm{AV}$, Ito D, et al. Distinct contributions of TNF and LT cytokines to the development of dendritic cells in vitro and their recruitment in vivo. Blood 2003; 101: 1477-1483.

10. Browning JL, Allaire N, Ngam-Ek A, Notidis E, Hunt J, Perrin S and Fava RA. Lymphotoxin-beta receptor signaling is required for the homeostatic control of HEV differentiation and function. Immunity 2005; 23: 539-550.

11. Kang HS, Chin RK, Wang Y, Yu P, Wang J, Newell KA and Fu YX. Signaling via LT $\beta R$ on the lamina propria stromal cells of the gut is required for IgA production. Nat Immunol 2002; 3: 576-582.

12. Stopfer P, Obermeier F, Dunger N, Falk W, Farkas S, Janotta $\mathrm{M}$, et al. Blocking lymphotoxin-beta receptor activation diminishes inflammation via reduced mucosal addressin cell adhesion molecule-1 (MAdCAM-1) expression and leucocyte margination in chronic DSS-induced colitis. Clin Exp Immunol 2004; 136: 21-29.

13. Banks TA, Rickert S, Benedict CA, Ma L, Ko M, Meier J, et al. A lymphotoxin-IFN-beta axis essential for lymphocyte survival revealed during cytomegalovirus infection. J Immunol 2005; 174: $7217-7225$.

14. White A, Carragher D, Parnell S, Msaki A, Perkins N, Lane P, et al. Lymphotoxin a-dependent and -independent signals regulate stromal organizer cell homeostasis during lymph node organogenesis. Blood 2007; 110: 1950-1959.

15. Lorenz RG, Chaplin DD, McDonald KG, McDonough JS and Newberry RD. Isolated lymphoid follicle formation is inducible and dependent upon lymphotoxin-sufficient B lymphocytes, lymphotoxin beta receptor, and TNF receptor I function. J Immunol 2003; 170: 5475-5482.

16. Scheu S, Alferink J, Potzel T, Barchet W, Kalinke U and Pfeffer $\mathrm{K}$. Targeted disruption of LIGHT causes defects in costimulatory $\mathrm{T}$ cell activation and reveals cooperation with lymphotoxin beta in mesenteric lymph node genesis. J Exp Med 2002; 195 : 1613-1624.

17. Ishikawa F, Yasukawa M, Lyons B, Yoshida S, Miyamoto T, Yoshimoto G, et al. Development of functional human blood and immune systems in NOD/SCID/IL2 receptor \{gamma\} chain(null) mice. Blood 2005; 106: 1565-1573.

18. Traggiai E, Chicha L, Mazzucchelli L, Bronz L, Piffaretti JC, Lanzavecchia A and Manz MG. Development of a human adaptive immune system in cord blood cell-transplanted mice. Science 2004; 304: 104-107.

19. Wege AK, Ernst W, Eckl J, Frankenberger B, VollmannZwerenz A, Männel DN, et al. Humanized tumor mice-A new model to study and manipulate the immune response in advanced cancer therapy. Int J Cancer 2011; 129: 2194-2206.

20. Browning JL, Sizing ID, Lawton P, Bourdon PR, Rennert PD, Majeau GR, et al. Characterization of lymphotoxin-alpha beta $\alpha$ 
complexes on the surface of mouse lymphocytes. J Immunol 1997; 159: 3288-3298.

21. Masopust D, Vezys V, Marzo AL and Lefrancois L. Preferential localization of effector memory cells in nonlymphoid tissue. Science 2001; 291: 2413-2417.

22. Chapman TJ and Topham DJ. Identification of a unique population of tissue-memory CD $4+\mathrm{T}$ cells in the airways after influenza infection that is dependent on the integrin VLA-1. J Immunol 2010; 184: 3841-3849.

23. Zhou P, Hwang KW, Palucki D, Kim O, Newell KA, Fu YX and Alegre ML. Secondary lymphoid organs are important but not absolutely required for allograft responses. Am J Transplant 2003; 3: 259-266.

24. Kusmartsev S, Nagaraj S and Gabrilovich DI. Tumor-associated $\mathrm{CD} 8+\mathrm{T}$ cell tolerance induced by bone marrow-derived immature myeloid cells. J Immunol 2005; 175: 4583-4592.

25. Serafini P, Borrello I and Bronte V. Myeloid suppressor cells in cancer: recruitment, phenotype, properties, and mechanisms of immune suppression. Semin Cancer Biol 2006; 16: 53-65.

26. Gabrilovich DI, Bronte V, Chen SH, Colombo MP, Ochoa A, Ostrand-Rosenberg $\mathrm{S}$ and abd Schreiber H. The terminology issue for myeloid-derived suppressor cells. Cancer Res 2007; 67: 425.

27. Schmid M, Wege AK and Ritter U. Characteristics of "Tip-DCs and MDSCs" and their potential role in leishmaniasis. Front Microbiol 2012; 3: 74.

28. Gabrilovich DI and Nagaraj S. Myeloid-derived suppressor cells as regulators of the immune system. Nat Rev Immunol 2009; 9: 162-174.

29. Serafini P, Mgebroff S, Noonan K and Borrello I. Myeloidderived suppressor cells promote cross-tolerance in B-cell lymphoma by expanding regulatory $\mathrm{T}$ cells. Cancer Res 2008; 68: $5439-5449$.

30. Kusmartsev S and Gabrilovich DI. Immature myeloid cells and cancerassociated immune suppression. Cancer Immunol Immunother 2002; 51: 293-298.

31. Ezernitchi AV, Vaknin I, Cohen-Daniel L, Levy O, Manaster E, Halabi A, et al. TCR zeta down-regulation under chronic inflammation is mediated by myeloid suppressor cells differentially distributed between various lymphatic organs. J Immunol 2006; 177 : 4763-4772.

32. Bingisser RM, Tilbrook PA, Holt PG and Kees UR. Macrophage-derived nitric oxide regulates $\mathrm{T}$ cell activation via reversible disruption of the Jak3/STAT5 signaling pathway. J Immunol 1998; 160: 5729-5734.

33. Apolloni E, Bronte V, Mazzoni A, Serafini P, Cabrelle A, Segal DM, et al. Immortalized myeloid suppressor cells trigger apoptosis in antigen-activated T lymphocytes. $J$ Immunol 2000; 165 : 6723-6730.

34. Young MR, Wright MA, Matthews JP, Malik I and Prechel M. Suppression of $\mathrm{T}$ cell proliferation by tumor-induced granulocyte- macrophage progenitor cells producing transforming growth factor-b and nitric oxide. J Immunol 1996; 156: 1916.

35. Kusmartsev $\mathrm{S}$ and Gabrilovich DI. Immature myeloid cells and cancerassociated immune suppression. Cancer Immunol Immunother 2002; 51: 293-298.

36. Bronte V, Serafini P, Apolloni E and Zanovello P. Tumorinduced immune dysfunctions caused by myeloid suppressor cells. J Immunother 2001; 24: 431-446.

37. al-Ramadi BK, Brodkin MA, Mosser DM and Eisenstein TK. Immunosuppression induced by attenuated Salmonella. Evidence for mediation by macrophage precursors. J Immunol 1991; 146: $2737-2746$.

38. Angulo I, Jimenez-Diaz MB, Garcia-Bustos JF, Gargallo D, de las Heras FG, Munoz-Fernandez MA and Fresno M. Candida albicans infection enhances immunosuppression induced by cyclophosphamide by selective priming of suppressive myeloid progenitors for NO production. Cell Immunol 2002; 218: 46-58.

39. Brys L, Beschin A, Raes G, Ghassabeh GH, Noël W, Brandt J, et al. Reactive oxygen species and 12/15-lipoxygenase contribute to the antiproliferative capacity of alternatively activated myeloid cells elicited during helminth infection. J Immunol 2005; 174: 6095-6104.

40. Billiau AD, Fevery S, Rutgeerts O, Landuyt W and Waer M. Transient expansion of Mac1 + Ly6-G + Ly6-C + early myeloid cells with suppressor activity in spleens of murine radiation marrow chimeras: possible implications for the graft-versushost and graft-versus-leukemia reactivity of donor lymphocyte infusions. Blood 2003; 102: 740-748.

41. Zhu B, Bando Y, Xiao S, Yang K, Anderson AC, Kuchroo VK and Khoury SJ. CD11b + Ly-6C(hi) suppressive monocytes in experimental autoimmune encephalomyelitis. J Immunol 2007; 179: 5228-5237.

42. Haile LA, von Wasielewski R, Gamrekelashvili J, Krüger C, Bachmann O, Westendorf AM, et al. Myeloid-derived suppressor cells in inflammatory bowel disease: a new immunoregulatory pathway. Gastroenterology 2008; 135: 871-881. 